\title{
Exercise Programs Targeting Scapular Kinematics and Stability Are Effective in Decreasing Neck Pain: A Critically Appraised Topic
}

\author{
Chris M. Edwards
}

\begin{abstract}
Clinical Scenerio: Neck pain is a costly symptom in both civilian and military worlds. While traditional treatments include deep neck flexor stabilizing exercises, manual therapy, electrical therapy, and other nonsurgical interventions, scapular orientation and stability training has emerged as a possible tool to reduce neck pain severity. Methods that can be coached at a distance could be of value in virtual appointments or circumstances where access to a qualified manual therapist is limited. Focused Clinical Question: What is the effectiveness of including exercise programs targeting scapular kinematics and stability to decrease neck pain? Summary of Key Findings: Exercise programs targeting scapular kinematics and stability, with coaching and individualized progressions, appear to reduce neck pain severity. Clinical Bottom Line: Evidence supports the inclusion of exercises for scapular kinematics and stability at a prescription of 3 sessions per week, with a duration of 4 or 6 weeks. Exercise programs should include a "learning" or coaching phase to ensure exercises are performed as intended, and exercise progressions should be based on participant ability rather than predetermined timelines. Further research is needed to better understand the benefits of this potential strategy and the statistical impact of scapular-focused exercise interventions on neck pain in specific populations like military and athletes. Strength of Recommendation: There is 'Fair' to 'Good' evidence from 2 level $1 \mathrm{~b}$ single-blind randomized control studies and 1 level $2 \mathrm{~b}$ pre-post test control design study supporting the inclusion of exercise programs targeting scapular kinematics and stability to decrease chronic neck pain severity.
\end{abstract}

Keywords: reconditioning, kinetic chain, military, pain reduction

\section{Clinical Scenario}

Neck pain affects both civilian and military personnel, with a 1 -year prevalence estimated at $26 \%$ to $37 \%$ and up to $62 \%$, respectively. ${ }^{1}$ The significantly higher incidence rate in military personnel has brought to light a need for effective treatment and mitigating protocols. This is especially true for military trades like pilots and aircrew, who are at a significantly higher risk of experiencing chronic neck pain. ${ }^{1,2}$ The financial burden of training an individual pilot is approximately $\$ 15.2$ million, and the inability to deploy poses an even greater cost to operational effectiveness. ${ }^{2}$ Determining treatment and mitigation protocols to reduce neck pain is critical for the retention of these personnel. By identifying exercise programs that yield significant improvements to neck pain severity in other populations, strategies to support military personnel can be developed and trialed.

While traditional treatments include deep neck flexor stabilizing exercises, manual therapy, electrical therapy, and other nonsurgical interventions, scapular orientation and motion is getting an increasing amount of attention to reduce the symptoms and disability associated with neck pain. ${ }^{3-5}$ This shift in treatment is likely due to increasing evidence connecting strategies targeting scapular dyskinesis and alignment impairments with decreases in neck and shoulder pain symptoms..$^{3,4,6}$

The most commonly administered measurement of neck pain disability is the Neck Disability Index (NDI). ${ }^{7}$ The NDI consists of 10 questions assessing functional activities, symptoms, and concentration, and it contains good content validity in patients with chronic, nontraumatic neck pain. ${ }^{7}$ The Visual Analogue Scale (VAS) is a $10-\mathrm{cm}$ line

Edwards (Cedward5@uottawa.ca) is with Concordia University Chicago, River Forest, IL, USA; and the University of Ottawa, Ottawa, ON, Canada. with "No Pain" beside the 0 and "Most intense pain imaginable" beside the 10, where the individual points to where their pain level is. ${ }^{8,9}$ The Numerical Pain Rating Scale (NRS) is similar to the VAS, but the individual uses a NRS to measure their pain. ${ }^{10}$ With virtual interventions and situations that do not allow for in-person access to qualified therapists and applied manual therapy, methods that can be coached at a distance could be of value. The purpose of this critically appraised topic (CAT) is to explore the effectiveness of exercise interventions targeting the scapular kinematic NDI, VAS, and NRS scores for neck pain.

\section{Focused Clinical Question}

What is the effectiveness of including exercise programs targeting scapular kinematics and stability to decrease neck pain?

\section{Summary of Search, "Best" Evidence Appraised, and Key Findings}

- The literature was searched to identify peer-reviewed articles that investigated the effectiveness of exercise programs targeting scapular kinematics and control in individuals with chronic neck pain.

- Of the 74 identified articles, 58 were excluded based on the title and abstract, 9 were excluded as article was not available in English, 2 were excluded based on evidence quality, and 2 were excluded as manual therapy including soft tissue mobilization was included in the intervention. Of the included articles, 2 were randomized control trials and 1 was a pre-post test control design.

- Exercise programs targeting the scapular motion and stabilization of 3 training sessions for 4 to 6 weeks decreased neck pain severity. 
- Exercise programs include a "learning" phase where participants are coached in some capacity, and progressions were individualized rather than based on a predetermined timeline.

\section{Evidence Quality Assessment}

The studies included were assessed with the Oxford Centre for Evidence-Based Medicine levels of evidence (2009) and evaluated using PEDro (1999).

\section{Clinical Bottom Line}

Based on the available literature, there are good to excellent levels of evidence to support the inclusion of exercise programs targeting scapular kinematics and stability to decrease pain in individuals with chronic neck pain. ${ }^{11-13}$ The current evidence included individuals with chronic neck pain for a minimum of 6 weeks with and without scapular dyskinesis pain. ${ }^{11-13}$ All protocols in the studies reviewed for this article included 3 sessions per week, with a duration of $4^{11}$ and $6^{12,13}$ weeks. All exercise programs included a "learning" or coaching phase to ensure that the participants were performing exercises and movements as intended by the therapist and researchers and that progressions were individualized rather than based on timeline-determined pain. ${ }^{11-13}$ Further research is needed to identify specific guidelines, limitations, and applications for the inclusion of scapular-focused exercise interventions included for neck pain reduction.

\section{Strength of Recommendation}

Based on the Oxford Centre for Evidence-Based Medicine Scale, level $1 \mathrm{~b}$ and $2 \mathrm{~b}$ evidence exists. ${ }^{14}$

\section{Search Strategy}

A database search was conducted in July 2020 to include peerreviewed publications dating to January 2016. The search terms used were

- $\underline{\mathbf{P}}$ - Individuals with neck pain

- I - Exercise program targeting scapular kinematics and/or stability

- $\underline{\mathbf{C}}-\mathrm{N} / \mathrm{A}$

- $\underline{\mathbf{O}}$ - Neck pain (NDI, VAS, and NRS)

\section{The Sources Searched}

- EBSCOhost

- PubMed

- Human Kinetics Journals

- Omni

- Google Scholar

\section{Inclusion Criteria}

- Studies classified as level 2 evidence or higher on the Oxford Centre for Evidence-Based Medicine Scale ${ }^{14}$

- PEDro scale rating "fair" (4-5) or above; PEDro is applied for randomized control trials only ${ }^{15}$

- Studies that identify exercise programs that target scapular motion or kinematics focus as treatment

- Studies that include VAS, NRS, and/or NDI as an outcome measure

\section{Exclusion Criteria}

- Studies that involved children or older adults (aged $60 \mathrm{y}$ and older)

- Studies using exercise in combination with other therapeutic treatments (massage therapy, palpation, acupuncture, etc)

- Studies involving surgical intervention

- Articles published prior to January 2016

- The Oxford 2011 Levels of Evidence, level 3 or lower ${ }^{14}$

- PEDro score of "poor" (0-4); PEDro is applied for randomized control trials only 15

\section{Results of Search}

The search of the literature returned 74 possible studies for inclusion. Three studies met the inclusion criteria (Table 1). The studies included were identified as best evidence and selected for inclusion in this CAT.

\section{Best Evidence}

As described in Table 2, the following studies were identified as the "best" evidence and selected for inclusion in the CAT. These studies were selected as they adhered to inclusion/exclusion requirements.

\section{Summary of Best Evidence}

The characteristics of the included studies are described in Table 2.

\section{Implications for Practice, Education, and Future Research}

The results of the 3 studies included in the CAT indicate that exercise programs targeting scapular kinematics and stability are effective at decreasing neck pain. While specific exercise and movement prescription varied between studies, each intervention

Table 1 Summary of Study Designs of Articles Retrieved

\begin{tabular}{|c|c|c|c|}
\hline $\begin{array}{l}\text { Level of evidence (Oxford Centre } \\
\text { for Evidence-Based Medicine) }{ }^{14}\end{array}$ & $\begin{array}{l}\text { Study design/methodology } \\
\text { of articles retrieved }\end{array}$ & Number located & Author \\
\hline Level $1 b$ & Single-blind randomized control study & 2 & $\begin{array}{l}\text { Derakhshani et al } \\
\text { Derakhshani et } \mathrm{al}^{13}\end{array}$ \\
\hline Level $2 b$ & Pre-post test control design & 1 & Ashwini et al ${ }^{11}$ \\
\hline
\end{tabular}


Table 2 Characteristics of Included Studies

\begin{tabular}{|c|c|c|c|}
\hline Author(s) & Ashwini et al ${ }^{11}$ & Derakhshani et al ${ }^{12}$ & Derakhshani et al ${ }^{13}$ \\
\hline Study design & Pre-post test control design & RCT & RCT \\
\hline $\begin{array}{l}\mathrm{N} \text {, males: } \\
\text { females }\end{array}$ & $27,11: 16$ & $42,27: 15$ & $140,140: 0$ \\
\hline $\begin{array}{l}\text { Age range, } \\
\text { average age }\end{array}$ & $18-50$ y, 31.26 (5.77) & $20-26$ y, 22.64 (1.69) & $21-27$ y, 23.41 (1.88) \\
\hline $\begin{array}{l}\text { Intervention } \\
\text { frequency, } \\
\text { duration }\end{array}$ & 3 sessions/wk, 4 wk & 3 sessions/wk, $6 \mathrm{wk}$ & 3 sessions/wk, $6 \mathrm{wk}$ \\
\hline $\begin{array}{l}\text { Intervention } \\
\text { group } \\
\text { exercises }\end{array}$ & $\begin{array}{l}\text { Week 1: } \\
\text { (1) Scapula position training } \\
\text { with tactile and verbal cues } \\
\text { Weeks } 1 \text { and 2: } \\
\text { (1) Prone extension } \\
\text { (2) External rotation in the } \\
\text { side-lying position } \\
\text { (3) Forward flexion in the } \\
\text { side-lying position } \\
\text { (4) Horizontal abduction with } \\
\text { external rotation in the prone } \\
\text { position } \\
\text { Weeks } 3 \text { and } 4 \\
\text { (1) Individualized stretching }\end{array}$ & $\begin{array}{l}\text { Group 1: SUREE with visual feedback } \\
\text { Group 2: SUREE without visual feedback }\end{array}$ & $\begin{array}{l}\text { Group 1: } \\
\text { (1) SUREE } \\
\text { (2) Shrug exercise } \\
\text { Group 2: } \\
\text { (1) SUREE } \\
\text { (2) Shrug exercise } \\
\text { (3) PCSPT } \\
\text { (4) MSDW }\end{array}$ \\
\hline $\begin{array}{l}\text { Control } \\
\text { group } \\
\text { exercises }\end{array}$ & N/A & $\begin{array}{l}\text { (1) At-home exercises based on postural cor- } \\
\text { rection during daily activities } \\
\text { (2) Lectures informing on activities promoting } \\
\text { general health }\end{array}$ & $\begin{array}{l}\text { (1) Chin-talk } \\
\text { (2) Push-up } \\
\text { (3) Shoulder shrug }\end{array}$ \\
\hline $\begin{array}{l}\text { Main find- } \\
\text { ings within } \\
\text { group }\end{array}$ & $\begin{array}{l}\text { NRS: } \\
\text { Significant improvement of } \\
4.81(1.07)(P<.001) \\
\text { NDI: } \\
\text { Significant improvement of } \\
24.47 \%(8.46)(P<.001)\end{array}$ & $\begin{array}{l}\text { VAS: } \\
\text { Group 1: Significant improvements by } 2.35 \\
(0.84)(P<.001) \\
\text { Group 2: Significant improvements by } 2.35 \\
(0.74)(P<.001) \\
\quad \text { Control group: No significant change }(0.035 \\
\text { [0.74], } P=.10)\end{array}$ & $\begin{array}{l}\text { VAS: } \\
\text { Group 1: Significant improvements }(1.75 \\
[0.86], P=.000) \\
\text { Group 2: Significant improvements }(2.50 \\
[1.16], P=.000) \\
\text { Control group: No significant changes }(0.16 \\
[0.57], P=.339)\end{array}$ \\
\hline $\begin{array}{l}\text { Main find- } \\
\text { ings between } \\
\text { group }\end{array}$ & N/A & $\begin{array}{l}\text { No significance between group } 1 \text { and group } 2 \\
(P>.99) \\
\text { Significant differences between control and both } \\
\text { intervention groups }(P<.001)\end{array}$ & $\begin{array}{l}\text { No significance between intervention group } 1 \\
\text { and group } 2(0.903, P=.019) \\
\text { Significant differences favoring intervention } \\
\text { group } 1(1.277, P=.002) \text { and group } 2(2.180, \\
P=.001) \text { against the control group }\end{array}$ \\
\hline $\begin{array}{l}\text { Level of } \\
\text { evidence }^{14}\end{array}$ & $2 b$ & $1 \mathrm{~b}$ & $1 b$ \\
\hline $\begin{array}{l}\text { Validity } \\
\text { score }\end{array}$ & Fair $^{16}$ & PEDro $6 / 10^{15}$ & PEDro $5 / 10^{15}$ \\
\hline Conclusion & $\begin{array}{l}4 \text { wk of scapular stabilizing } \\
\text { exercise shows significant } \\
\text { improvement to NDI and NRS } \\
\text { scores }\end{array}$ & $\begin{array}{l}6 \text { wk of SUREE with and without visual feedback } \\
\text { significantly decrease neck pain. No significant } \\
\text { differences if exercises performed with or with- } \\
\text { out visual feedback }\end{array}$ & $\begin{array}{l}6 \text { wk of SUREE and shrug exercise program, } \\
\text { with and without passive interventions, can } \\
\text { significantly decrease neck pain intensity, EMG, } \\
\text { and scapular kinematics } \\
\text { Inclusion of passive scapular correction inter- } \\
\text { ventions superior compared with SUREE and } \\
\text { shrug exercises alone }\end{array}$ \\
\hline
\end{tabular}

Abbreviations: EMG, electromyography; MSDW, mobilization of scapula during wall slide exercise, standing in front of a wall with shoulders and elbows flexed at $90^{\circ}$, participants were instructed to slide upward while pushing forearms into wall. Investigator brought scapula to more abduction, upward rotation, and elevation, position was held for $10 \mathrm{~s}$ before returning to starting position; NDI, Neck Disability Index; NRS, Numeric Pain Rating Scale; PCSPT, participant sat with hands supported to allow the elevation and abduction of the scapula taken to elevation and abduction with hands supported; RCT, randomized control trials; SUREE, Scapular Upward Rotation and Elevation Exercise program, including the abduction with lateral rotation wall slide, medial/lateral rotation in adduction, active, and passive elevation, and active assisted elevation; VAS, Visual Analogue Scale.

protocol included a "coaching" phase where participants learned scapular placement and movement control.

All included studies-based movement and exercise progressions on individual progress, not predetermined timelines, and occurred at a frequency of 3 sessions per week for $4^{11}$ and 6 weeks. ${ }^{12,13}$ Coaching and feedback included performing exercises in front of a mirror for visual feedback, ${ }^{12}$ tactile cues from a physical therapist, ${ }^{11-13}$ and verbal cues from a physical therapist. ${ }^{11-13}$ 
Seemingly, however, not all feedback and cues are equal. The Scapular Upward Rotation and Elevation Exercise program implemented by Derakhshani et $\mathrm{al}^{12}$ demonstrated significant improvements to VAS scores $(P<.001)$, with no significant difference if exercises were performed with and without visual feedback $(P>.99)$. Derakhshani et $\mathrm{al}^{13}$ indicated a potential benefit for the inclusion of sensorimotor training with and without passive intervention aimed at addressing scapular position and mobilization. However, sensorimotor training with passive intervention yielded statistically superior VAS score improvements (1.75 [0.86], $P=.000)$, when compared with the significant improvements of sensorimotor training alone (2.50 [1.16], $P=.000)$. Sensorimotor training with and without passive intervention were also favoured over conventional exercise training (chin-talk, push-up, and shoulder shrug exercises, 3 sessions per wk), which did not yield significant changes (0.16 [0.57], $P=.339)$.

The commonalities of a coaching phase, 3 sessions per week, and individualized exercise and movement progression indicate a potential benefit in including exercise programs targeting scapular kinematics and stability to treat neck pain. For at-risk populations with unpredictable life demands like the military, the protocols outlined in all 3 studies would be accessible, as they require minimal time and resources. These findings could also be of value in situations where appointments must occur virtually or when qualified practitioners are not present to provide palpation and other manual therapies. Ashwini et al $^{11}$ demonstrated a scapular-focused exercise program's ability to yield NDI improvements of $24.47 \%$ at $95 \% \mathrm{CI}$, after only 4 weeks of intervention. While the other 2 studies were slightly longer in duration, a 4- to 6-week timeline could be helpful in planning a return to work/duty/play and could aid progression from corrective exercise to strength and conditioning programs. Further research is needed to define the limitations of this potential strategy and the significance of scapular-focused exercise interventions on neck pain in specific populations like the military and athletes. As the intention of this CAT was to examine interventions including only exercises and cueing, a review examining the combination of manual therapy and other modalities is recommended.

This CAT should be reviewed in 2 years to determine whether additional best research evidence has been published that could aid in answering the focused clinical question.

\section{References}

1. Murray M, Lange B, Chreiteh SS, et al. Neck and shoulder muscle activity and posture among helicopter pilots and crew-members during military helicopter flight. J Electromyogr Kinesiol. 2016;27: 10-17. doi:10.1016/j.jelekin.2015.12.009

2. Riches A, Spratford W, Witchalls J, Newman PA. Systematic review and meta-analysis about the prevalence of neck pain in fast jet pilots. Aerosp Med Hum Perform. 2019;90(10):882-890. doi:10.3357/ AMHP.5360.2019

3. Andersen CH, Andersen LL, Zebis MK, Sjøgaard G. Effect of scapular function training on chronic pain in the neck/shoulder region: a randomized controlled trial. J Occup Rehabil. 2014;24(2): 316-324. doi:10.1007/s10926-013-9441-1

4. Lluch E, Arguisuelas MD, Quesada OC, et al. Immediate effects of active versus passive scapular correction on pain and pressure pain threshold in patients with chronic neck pain. J Manipulative Physiol Ther. 2014;37(9):660-666. doi:10.1016/j.jmpt.2014. 08.007

5. Zakharova-Luneva E, Jull G, Johnston V, O’Leary S. Altered trapezius muscle behavior in individuals with neck pain and clinical signs of scapular dysfunction. J Manipulative Physiol Ther. 2012;35(5): 346-353. doi:10.1016/j.jmpt.2012.04.011

6. Kibler WB, Ludewig PM, McClure PW, Michener LA, Bak K, Sciascia AD. Clinical implications of scapular dyskinesis in shoulder injury: the 2013 consensus statement from the "Scapular Summit." Br J Sports Med. 2013;47:877-885. PubMed ID: 23580420 doi:10. 1136/bjsports-2013-092425

7. Qureshi S. (2018). CORR Insights ${ }^{\circledR}$ : What are the MCIDs for PROMIS, NDI, and ODI instruments among patients with spinal conditions? Clin Orthop Relat Res. 2018;476(10):2037-2039. doi:10. 1097/CORR.0000000000000465

8. Le May B. Comparison of the psychometric properties of 3 pain scales used in the pediatric emergency department: visual analogue scale, faces pain scale-revised, and colour analogue scale. Pain. 2018; 159(8):1508-1517. doi:10.1097/j.pain.0000000000001236

9. En MCC, Clair DA, Edmondston SJ. Validity of the neck disability index and neck pain and disability scale for measuring disability associated with chronic, non-traumatic neck pain. Man Ther. 2009; 14(4):433-438. doi:10.1016/j.math.2008.07.005

10. McCaffery M, Pasero C. Teaching patients to use a numerical pain-rating scale. Am J Nurs. 1999;99(12):22. doi:10.1097/01.NAJ.0000324375. 02027.9f

11. Ashwini TM, Karvannan H, Prem V. Effects of movement impairment based treatment in the management of mechanical neck pain. J Bodyw Mov Ther. 2018;22(2):534-539. doi:10.1016/j. jbmt.2017.07.007

12. Derakhshani A, Letafatkar A, Khosrokiani Z. Comparing the effects of SUREE programs on people with scapular downward rotation syndrome: a randomized clinical trial. J Sport Rehabil. 2019;28(8): 787-795. doi:10.1123/jsr.2018-0051

13. Derakhshani A, Letafatkar A, Abbasi A. Comparison of the effects of sensorimotor training programs on pain, electromyography and kinematics in patients with scapular downward rotation syndrome. Phys Ther Sport. 2018;34:66-75. doi:10.1016/j.ptsp.2018. 08.011

14. OCEBM Levels of Evidence Working Group. The Oxford 2011 levels of evidence. Oxford centre for evidence-based medicine. 2011. http:// www.cebm.net/index.aspx?o=5653. Accessed July, 2020.

15. PEDro Physiotherapy Evidence Database. PEDro scale. 1999, June 21. https://pedro.org.au/english/resources/pedro-scale/. Accessed July, 2020.

16. National Heart, Lung, and Blood Institute. Quality assessment tool for before-after (pre-post) studies with no control group. https://www. nhlbi.nih.gov/health-topics/study-quality-assessment-tools. Accessed January 27, 2021. 